\title{
Screening for Hypoglycemic Activity on The Leaf Extracts of Nine Medicinal Plants: In-Vivo Evaluation
}

\author{
ADITYA ARYA,,${ }^{1,2}$ MAHMOOD AMEEN ABDULLAH, ${ }^{3}$ BATOUL SADAT \\ HAERIAN, ${ }^{1}$ AND MUSTAFA ALI MOHD ${ }^{1 *}$
}

${ }^{1}$ Department of Pharmacology, Faculty of Medicine, University of Malaya, Kuala Lumpur 50603, Malaysia

${ }^{2}$ Department of Pharmacy, Faculty of Medicine, University of Malaya, Kuala Lumpur

50603, Malaysia

${ }^{3}$ Department of Molecular Medicine, Faculty of Medicine, University of Malaya, Kuala Lumpur 50603, Malaysia

aditya@um.edu.my

adityaarya18@gmail.com

Received 3 November 2011; Accepted 7 January 2012

\begin{abstract}
The traditional use of certain plants by the tribal community in central India involves using the young leaves for several ailments, including hyperglycaemia; this study was performed to evaluate the effects of the leaf extracts from 9 such plants in the management of diabetes. Initially, hypoglycemic screening was performed on normal rats whose blood glucose levels were measured before and after oral or intraperitoneal (i.p.) administration of the extracts at different periods. The plants were screened at doses of $250 \mathrm{mg} / \mathrm{kg}$ i.p. or $500 \mathrm{mg} / \mathrm{kg}$ orally. Of these, only Centratherum anthelminticum (Asteraceae), Cissus quadrangularis (Vitaceae), and Woodfordia fruticosa Kurz (Lythraceae) significantly reduced postprandial blood glucose levels in normal glycemic rats $(P<0.001)$, with slight reductions effected by Sida acuta Burm F. $(P=0.002)$ and Parthenium hysterophorus $L .(P=0.017)$. The extracts that reduced postprandial blood glucose levels both orally and i.p. in the hypoglycemic screening tests were evaluated for glucose challenge in glucose tolerance tests with i.p and oral administration in overnight-fasted normal rats. The results of these tests potentiate the screening data in the management of diabetes mellitus, which requires further studies on the plants that yielded positive results to determine the active compounds in the different plant parts that are responsible for the activity.
\end{abstract}

Keywords: Hypoglycemic activity, Traditional medicine, Herbals, Glucose tolerance test,Centratherum anthelminticum, Cissus quadrangularis, Woodfordia fruticosa. 


\section{Introduction}

Diabetes mellitus (DM) has attained pestilencein the current century. It is the most prevalent disease in the world affecting 7\% of population, or 285 million people worldwide. It is predicted that this number will exceed to 435 million in $2030 .{ }^{1}$ Approximately, $90-95 \%$ of patients with diabetes have type 2 diabetes (T2D) or non-insulin dependent diabetes mellitus. T2D is accounting for a combination of insulin resistance and an adequate compensatory insulin secretory response. ${ }^{2}$ Oral hypoglycaemics such as biguanides, sulfonylureas, and thiazolidinediones are available for the treatment of type 2 diabetes, but can also cause adverse effects and be ineffective against some long-term diabetic complications. The World Health Organization recommends the use of traditional and plant based medicines for the management of diabetes mellitus. ${ }^{3}$ Herbal medicine is an alternative method for the treatment of diabetes due to their perceived effectiveness, safety, affordability, and acceptability, with minimal side effects in clinical experience, and relatively low cost. ${ }^{4}$

More than 1200 plants are used in traditional medicine for their alleged hypoglycemic activity. Numerous studies have reported the anti-diabetic activity of plants. ${ }^{5}$ In the present study, the rationale for selecting the 9 plants studied was their traditional use by tribal people for conditions involving frequent urination and elevated blood glucose levels with symptoms such as weakness, mouth dryness, and conditions associated and arising from diabetes. The tribes are from villages in the Betul and Hoshangabad districts, which are surrounded by the Satpuda forest ranges, and located in the state of Madhya Pradesh, India. In these districts, villagers consume decoctions from the young leaves of these plants early in the morning for the treatment of diabetes as well as for other ailments. The treatment is particularly common and popular in tribes of the Gond community, where the plants are cultivated or found in abundance around their farms or in the jungles. The plants tested were Centratherum anthelminticum, Parthenium hysterophorus L., Xanthium strumarium L., and Vicoa indica Cass, which areall from the Asteraceae family, together with five others from different families: Woodfordia fruticosa Kurz (Lythraceae), Sida acuta Burm F. (Malvaceae), Vanda tessellata (Roxb.) (Orchidaceae), Madhuca indica (Sapotaceae), and Cissus quadrangularis (Vitaceae). There are several reports on the antidiabetic effects of different parts of C. anthelminticum, Parthenium hysterophorus L., Cissus quadrangularis, and Woodfordia fruticosa Kurz. ${ }^{6-11}$ The purpose of this study was to investigate and evaluate the potential of these plants leaves in suppressing elevated blood glucose levels in normoglycaemic and glucose-induced hyperglycaemic rats through the intraperitoneal (i.p.) and oral routes of administration.

\section{Materials and Methods}

\section{Plant Materials and Preparation of Plant Extracts}

Fresh leaves from the nine plants were collected from Amritum Bio-Botanica Herbs Research Laboratory Pvt. Ltd., in Jogli, Madhya Pradesh, India, authenticated by the company's quality control department, dried in maintained shade in a greenhouse for few days, ground into coarse powder, and then brought to the Department of Pharmacology in the Faculty of Medicine, University of Malaya, Kuala Lumpur, Malaysia, for further study. The dried, powdered samples were extracted with water: ethanol (80:20)using a soxhlet extractor, subsequently the obtained crude extracts were successively defatted with hexane and chloroform, before being extracted with methanol. The resulting methanol extracts were dried (evaporated) using a rotary evaporator (Rotavapor, Buchi) under reduced pressure at 
$40^{\circ} \mathrm{C}$ to yield a final methanolic extract, which was further stored at $-20^{\circ} \mathrm{C}$ prior to use. Before administration to the rats, each extract was diluted with water and filtered.

\section{Preliminary Phytochemical Screening}

A phytochemical screening test for alkaloids, flavonoids, saponins, phenols, tannins, and terpenoids using standard procedures was performed on the defatted leaf methanolic extracts to identify their chemical constituents. ${ }^{12}$

\section{Animals and Treatment}

Altogether, 400 Sprague-Dawley rats weighing (150-200 g) were procured from the Animal Care Unit, UMMC (University Malaya Medical Centre), Kuala Lumpur, Malaysia, and were acclimatized to laboratory conditions for 1 week. Rats were housed in polypropylene cages (6-7 rats/cage) under an ambient temperature of $23 \pm 3^{\circ} \mathrm{C}$ and $40-65 \%$ relative humidity with $12 \mathrm{~h}$ light and dark cycles. They were maintained on a standard pellet diet and water $a d$ libitum. Guidelines of the Guide for the Care and Use of Laboratory Animals were strictly followed throughout the study. The experimental protocol was approved by the UMMC Animal Ethics Committee (No: FAR/10/11/2008/AA(R)).

Acclimatized animals were divided into 2 sections, one for acute toxicity study, other section for hypoglycemic screening. Male animals were chosen for hypoglycemic screening test and allocated a carbohydrate-rich diet for 2 weeks before the experiments were started. Animals with postprandial blood glucose levels of $8-10 \mathrm{mmol} / \mathrm{L}$ were used for the screening test. Animals with either sex were selected for acute toxicity studies.

\section{Acute Oral and Intraperitoneal Toxicity Studies}

The oral and intraperitoneal acute toxicity tests of the extracts were determined in accordance with OECD (Organization for Economic Co-operation and Development) guidelines. The animals were starved overnight and divided into 36 groups $(n=6)$ and were injected intraperitoneally with extracts doses ranging $25-2500 \mathrm{mg} / \mathrm{kg}$ body weight and were fed with doses ranging $50-5000 \mathrm{mg} / \mathrm{kg}$ body weight. The rats were observed continuously for $2 \mathrm{~h}$ to assess their behavioural, neurological, and autonomic profiles and after 24 and 72 $\mathrm{h}$ to identify lethality.

\section{Determination of Postprandial Blood Glucose Levels in Normoglycaemic Rats}

Screening for hypoglycemic activity of the extracts was carried out by i.p and oral $(250 \mathrm{mg} / \mathrm{kg}$ and $500 \mathrm{mg} / \mathrm{kg}$ ) administration based on volume $(2 \mathrm{ml} / 200 \mathrm{~g}$ body weight $)$. Normal control animals received $\mathrm{NaCl} 0.9 \%$ while positive control animals were administered with insulin $(0.5 \mathrm{U} / \mathrm{kg})$ i.p. or glibenclamide $(50 \mathrm{mg} / \mathrm{kg})$ given orally.

Blood samples were collected from the tail by snipping, and blood glucose concentrations were determined in non-fasting conditions at different times after the above treatments by a glucose oxidase-peroxidase enzymatic method using a standardized glucometer (Accu-Check Performa, Roche Diagnostic Germany). An extract was deemed to have a hypoglycemic effect if the blood glucose levels of the test groups decreased significantly compared to that of the normal control group.

\section{Glucose Challenge (Glucose Tolerance Test)}

Intraperitoneal Glucose Tolerance Test (IPGTT) and Oral Glucose Tolerance Test (OGTT) were used to evaluate the effectiveness of the leaf extracts that had demonstrated hypoglycemic potential in the screening tests. Extracts $(250 \mathrm{mg} / \mathrm{kg}$ or $500 \mathrm{mg} / \mathrm{kg})$ were administered to overnight-fasted rats in doses of $2.0 \mathrm{ml} / 200 \mathrm{~g}$ (the control group was given $\mathrm{NaCl} 0.9 \%$ ). Blood glucose concentrations were measured before and at 120 and $210 \mathrm{~min}$, after i.p and oral extracts administration respectively. After this time point, oral glucose (3 
$\mathrm{g} / \mathrm{kg}$ ) was administered and blood glucose levels were measured at 30, 60, and $120 \mathrm{~min}$ in the IPGTT and at 60, 120, and $180 \mathrm{~min}$ in the OGTT.

\section{Statistical Analysis}

The results were calculated as mean \pm SEM and comparison of the data was carried out by 1-way and 2-way repeated measures ANOVA tests where appropriate (one factor repeated), with all pair-wise multiple comparison procedures (Student-Newman-Keuls method). Significance was considered to be $P<0.001$.

\section{Results and Discussion}

\section{Plants Extract Phytochemical Constituents}

Preliminary phytochemical analysis of methanolic extracts from the leaves of nine plants revealed the presence of flavonoids in all, except Sida acuta Burm F. and Vanda tessellata (Table 1). Similarly, phenolic and saponin compounds were present in all the leaves, while tannins were only absent in the Sida acuta Burm F. and Vicoa indica extracts. All the extracts, except that from Madhuca indicatested positive for alkaloids. Amongst the leaves, terpenoids were not seen in Vanda tessellata (Roxb.), Parthenium hysterophorus L., and Sida acuta Burm F. extracts.

Table 1. Phytochemical constituents of methanolic leaf extracts.

\section{Compounds}

\begin{tabular}{|c|c|c|c|c|c|c|c|}
\hline \multirow[b]{2}{*}{ Plants } & \multirow[b]{2}{*}{ Parts Used } & \multicolumn{6}{|c|}{ Compounds } \\
\hline & & 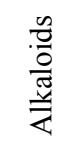 & 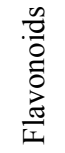 & $\begin{array}{l}\frac{n}{0} \\
\frac{0}{0} \\
\frac{d}{2}\end{array}$ & 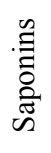 & 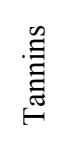 & $\begin{array}{l}\frac{0}{0} \\
0 \\
0 \\
0 \\
0 \\
\stackrel{0}{0}\end{array}$ \\
\hline Centratherum anthelminticum & Leaves & + & ++ & ++ & + & ++ & + \\
\hline Cissus quadrangularis & Leaves & + & + & + & + & + & ++ \\
\hline Woodfordia fruticosa Kurz & Leaves & + & + & + & + & + & + \\
\hline Madhuca indica & Leaves & NA & + & + & + & + & + \\
\hline Vicoa indica Cass & Leaves & + & + & + & + & NA & + \\
\hline Vanda tessellata (Roxb.) & Leaves & + & NA & + & + & + & NA \\
\hline Parthenium hysterophorus $L$. & Leaves & + & + & + & + & + & NA \\
\hline Sida acuta Burm F. & Leaves & + & NA & + & + & NA & NA \\
\hline Xanthium strumarium $L$. & Leaves & + & + & + & + & + & + \\
\hline
\end{tabular}

\section{Acute Oral and Intraperitoneal Toxicity Studies}

The acute oral and intraperitoneal toxicity studies demonstrated that the methanolic extracts from all of the selected plants leaf, other than Parthenium hysterophorus L., were non-toxic up to a dose of $2500 \mathrm{mg} / \mathrm{kg}$. For Parthenium hysterophorus $L$. the $\mathrm{LD}_{50}$ obtained via i.p administration was $2500 \mathrm{mg} / \mathrm{kg}$. Based on this finding, doses with $250 \mathrm{mg} / \mathrm{kg}$ and $500 \mathrm{mg} / \mathrm{kg}$ were chosen as the maximum dose for further experiments involving administration by the i.p and oral routes respectively. 


\section{Hypoglycemic Activity of Plants Leaf Extracts by i.p. and Oral Routes}

The results of the hypoglycemic activity of the leaf extracts on normal glycemic rats administered through the i.p. and oral routes are shown in Tables 2 and 3. Accordingly, after i.p. and oral administration of $\mathrm{NaCl} 0.9 \%$ to normal control rats, the blood glucose levels did not change within the different time intervals. Administration of i.p. insulin $(0.5 \mathrm{U} / \mathrm{kg})$ significantly reduced blood glucose levels for 1-2 hours, then increased it again. A similar finding was observed following oral administration of glibenclamide (50 $\mathrm{mg} / \mathrm{kg})$, but the level of blood glucose returned back only after $6 \mathrm{~h}(P<0.001)$ for all when compared to time 0 and normal control group at the same times. Out of the nine plants, three (C. anthelminticum, Cissus quadrangularis, and Woodfordia fruticosa Kurz) significantly altered blood glucose levels $(P<0.001)$, while four (Madhuca indica., Vicoa indica Cass, Vanda tessellata (Roxb.), and Xanthium strumarium L.) did not.

Intraperitoneal administration of $C$. anthelminticum, Cissus quadrangularis, and Woodfordia fruticosa Kurzextracts at $250 \mathrm{mg} / \mathrm{kg}$ dose produced various outcomes, the blood glucose levels of rats decreased from $9.3 \pm 0.11,8.8 \pm 0.19$, and $9.1 \pm 0.20 \mathrm{mmol} / \mathrm{L}$, respectively to $4.9 \pm 0.13,5.6 \pm 0.15$, and $5.2 \pm 0.18 \mathrm{mmol} / \mathrm{L}$ after the first hour. This reduction continued by the second hour to $4.6 \pm 0.23,5.3 \pm 0.13$, and $5.1 \pm 0.16 \mathrm{mmol} / \mathrm{L}$, respectively. Finally, unlike $C$. anthelminticum $(4.3 \pm 0.15 \mathrm{mmol} / \mathrm{L}$ after $3 \mathrm{~h})$, a slight increase in blood glucose levels was observed with Cissus quadrangularis and Woodfordia fruticosa Kurz extracts after the third hour $(5.5 \pm 0.19$ and $5.3 \pm 0.13 \mathrm{mmol} / \mathrm{L}$, respectively). A significant difference in blood glucose levels was observed after the first, second, and third hours following i.p. administration of C. anthelminticum, Cissus quadrangularis, and Woodfordia fruticosa Kurz extracts $(P<0.001)$ when compared to that of the normal control.

Table 2. Hypoglycemic activity of leaf extract by i.p. route in normal rats.

Group Blood glucose levels(mmol/L)at different time points (h)

\begin{tabular}{lccccc}
\cline { 2 - 5 } & \multicolumn{5}{c}{ Time (mean \pm SEM) } \\
\cline { 2 - 6 } & $8.9 \pm 0.09$ & $9.0 \pm 0.07$ & $8.8 \pm 0.24$ & $8.8 \pm 0.03$ & 0.856 \\
\hline Normal control (NaCl0.9\%) & $8.8 \pm 0.14$ & $4.4 \pm 0.19^{*}$ & $4.3 \pm 0.11^{*}$ & $5.0 \pm 0.07^{*}$ & $<0.001$ \\
Insulin 0.5 U/kg & $9.3 \pm 0.11$ & $4.9 \pm 0.13^{*}$ & $4.6 \pm 0.23^{*}$ & $4.3 \pm 0.15^{*}$ & $<0.001$ \\
Centratherum anthelminticum & $8.8 \pm 0.19$ & $5.6 \pm 0.15^{*}$ & $5.3 \pm 0.13^{*}$ & $5.5 \pm 0.19^{*}$ & $<0.001$ \\
Cissus quadrangularis & $9.1 \pm 0.20$ & $5.2 \pm 0.18^{*}$ & $5.1 \pm 0.16^{*}$ & $5.3 \pm 0.15^{*}$ & $<0.001$ \\
Woodfordia fruticosa Kurz & $8.9 \pm 0.12$ & $9.0 \pm 0.16$ & $8.7 \pm 0.21$ & $9.1 \pm 0.13$ & 0.420 \\
Madhuca indica & $9.2 \pm 0.10$ & $9.0 \pm 0.08$ & $8.8 \pm 0.21$ & $9.0 \pm 0.20$ & 0.443 \\
Vicoa indica Cass & $8.7 \pm 0.19$ & $8.5 \pm 0.19$ & $8.8 \pm 0.17$ & $8.7 \pm 0.10$ & 0.765 \\
Vanda tessellata (Roxb.) & $8.8 \pm 0.10$ & $8.9 \pm 0.11$ & $8.5 \pm 0.14$ & $8.6 \pm 0.10$ & 0.072 \\
Parthenium hysterophorus L. & $8.6 \pm 0.13$ & $8.4 \pm 0.11$ & $8.2 \pm 0.18$ & $8.7 \pm 0.74$ & 0.065 \\
Sida acuta Burm F. & $8.8 \pm 0.19$ & $9.0 \pm 0.27$ & $8.9 \pm 0.12$ & $8.8 \pm 0.17$ & 0.895 \\
Xanthium strumarium L. & & & & & \\
\hline
\end{tabular}

*Significant compared with time 0 and normal control $(P<0.001)$ group. 
In the same manner $C$. anthelminticum, Cissus quadrangularis, and Woodfordia fruticosa Kurz extracts demonstrated similar results with $500 \mathrm{mg} / \mathrm{kg}$ of oral administration, the blood glucose levels of rats decreased from $8.8 \pm 0.11,8.6 \pm 0.10$, and $9.0 \pm 0.16$ $\mathrm{mmol} / \mathrm{L}$, respectively, to $4.6 \pm 0.11,4.9 \pm 0.07$, and $4.8 \pm 0.10 \mathrm{mmol} / \mathrm{L}$ after the second hour. This reduction continued by the fourth hour to $4.5 \pm 0.14,5.1 \pm 0.07$, and $4.7 \pm 0.07$ $\mathrm{mmol} / \mathrm{L}$, respectively. Finally, a slight increase was observed at $6 \mathrm{~h}(4.7 \pm 0.17,5.4 \pm 0.16$, and $5.1 \pm 0.07 \mathrm{mmol} / \mathrm{L}$ ). A significant difference in blood glucose levels was observed after the second, fourth, and sixth hours of oral administration with these extracts $(P<0.001)$ when compared to that of the normal control group.

There was also a slight decrease in blood glucose levels by the Sida acuta Burm F. $(P=0.002)$ and Parthenium hysterophorus L. $(P=0.017)$ extracts after 2 and $4 \mathrm{~h}$ of oral administration, respectively.

Table 3. Hypoglycemicactivityofleaf extract by oral route in normal rats.

\begin{tabular}{lccccc}
\hline \multirow{2}{*}{ Group } & \multicolumn{5}{c}{ Blood glucose levels (mmol/L)at different time points (h) } \\
\cline { 2 - 6 } & \multicolumn{5}{c}{ Time (mean \pm SEM) } \\
\cline { 2 - 6 } & $9.1 \pm 0.12$ & $8.9 \pm 0.13$ & $9.2 \pm 0.17$ & $9.5 \pm 0.08$ & 0.059 \\
\hline Normal control (NaCl0.9\%) & $9.2 \pm 0.13$ & $4.4 \pm 0.06^{*}$ & $4.9 \pm 0.16^{*}$ & $5.9 \pm 0.12^{*}$ & $<0.001$ \\
Glibenclamide 50mg/kg & $8.8 \pm 0.11$ & $4.6 \pm 0.11^{*}$ & $4.5 \pm 0.14^{*}$ & $4.7 \pm 0.17^{*}$ & $<0.001$ \\
Centratherum anthelminticum & $8.6 \pm 0.10$ & $4.9 \pm 0.07^{*}$ & $5.1 \pm 0.07^{*}$ & $5.4 \pm 0.16^{*}$ & $<0.001$ \\
Cissus quadrangularis & $9.0 \pm 0.16$ & $4.8 \pm 0.10^{*}$ & $4.7 \pm 0.07^{*}$ & $5.1 \pm 0.07^{*}$ & $<0.001$ \\
Woodfordia fruticosa Kurz & $8.1 \pm 0.09$ & $8.3 \pm 0.17$ & $8.2 \pm 0.17$ & $8.4 \pm 0.16$ & 0.497 \\
Madhuca indica & $8.9 \pm 0.09$ & $9.2 \pm 0.06$ & $8.8 \pm 0.21$ & $9.0 \pm 0.20$ & 0.354 \\
Vicoa indica Cass & $8.7 \pm 0.19$ & $8.5 \pm 0.19$ & $8.5 \pm 0.08$ & $8.9 \pm 0.08$ & 0.285 \\
Vanda tessellata (Roxb.) & $9.5 \pm 0.08$ & $9.2 \pm 0.09^{\$}$ & $9.4 \pm 0.06^{\$}$ & $9.5 \pm 0.12$ & 0.017 \\
Parthenium hysterophorus L. & $8.6 \pm 0.13$ & $8.0 \pm 0.11^{\$}$ & $8.4 \pm 0.14^{\$}$ & $8.7 \pm 0.07$ & 0.002 \\
Sida acuta Burm F. & $9.2 \pm 0.13$ & $9.1 \pm 0.21$ & $9.4 \pm 0.16$ & $9.1 \pm 0.13$ & 0.747 \\
Xanthium strumarium L. & & & &
\end{tabular}

*Significant compared with time 0 and normal control $(P<0.001)$.

${ }^{\$}$ Significant difference between treatment times in each group.

\section{Intraperitoneal and Oral Glucose Tolerance Tests}

Intraperitoneal and oral glucose tolerance tests were used to evaluate the effectiveness of the extracts with hypoglycemic potential as identified in the screening tests. When $C$. anthelminticum, Cissus quadrangularis, and Woodfordia fruticosa Kurz extracts were administered to overnight-fasted normal rats, no alteration in blood glucose levels was observed until 120 and $210 \mathrm{~min}$ after i.p. $(250 \mathrm{mg} / \mathrm{kg})$ and oral $(500 \mathrm{mg} / \mathrm{kg})$ administration, respectively.

Thereafter, at $30 \mathrm{~min}$ of i.p glucose injection, the level of blood glucose were greatly elevated in the $(\mathrm{NaCl} 0.9 \%)$ treated normal control rats $(9.4 \pm 0.23 \mathrm{mmol} / \mathrm{L})$, followed by groups treated with Woodfordia fruticosa Kurz $(7.5 \pm 0.11 \mathrm{mmol} / \mathrm{L})$, Cissus quadrangularis 
$(7.1 \pm 0.13 \mathrm{mmol} / \mathrm{L})$ and $C$. anthelminticum $(6.4 \pm 0.21 \mathrm{mmol} / \mathrm{L})$, extracts(Fig. 1). Then at $60 \mathrm{~min}$, the blood glucose levels had decreased in $C$. anthelminticum $(4.8 \pm 0.19 \mathrm{mmol} / \mathrm{L})$, Cissus quadrangularis $(5.9 \pm 0.25 \mathrm{mmol} / \mathrm{L})$, Woodfordia fruticosa Kurz $(6.1 \pm 0.22$ $\mathrm{mmol} / \mathrm{L})$, as well as in the normal control $(8.5 \pm 0.15 \mathrm{mmol} / \mathrm{L})$ groups. In the same manner reduction continued and was higher in the groups administered with all the three extracts $(3.9 \pm 0.22,5.5 \pm 0.19$, and $5.1 \pm 0.15 \mathrm{mmol} / \mathrm{L}$, respectively) compared to that of normal control $(6.7 \pm 0.10 \mathrm{mmol} / \mathrm{L})$ rat sup until $120 \mathrm{~min}$. A significant difference in blood glucose levels was observed between the times for all the 3 extracts $(P<0.001)$ respectively, when compared with the normal control $(P<0.01)$ group.

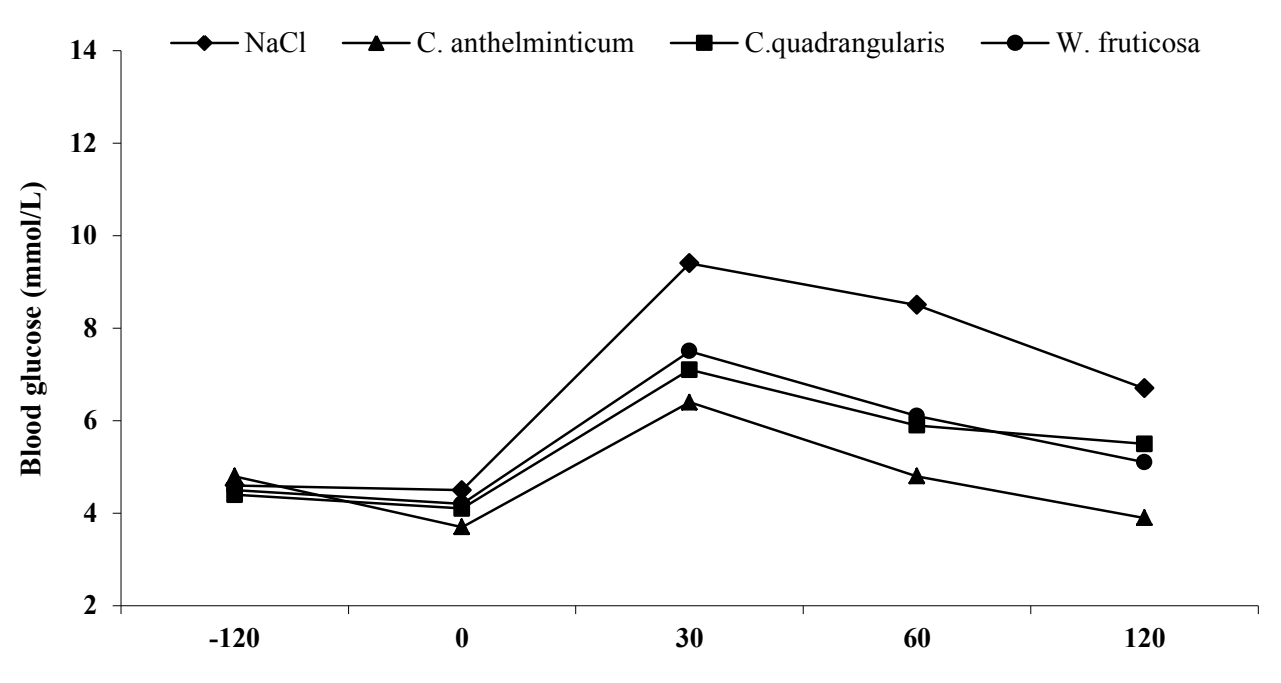

Time ( minutes)

Figure 1. Intra-peritoneal glucose tolerance test on $C$. anthelminticum, Cissus quadrangularis, and Woodfordia fruticosa Kurz extracts in normal fasted rats with glucoseinduced hyperglycemia. Data are mean \pm SE. $\mathrm{n}=6$ for each group. $(P<0.001)$ for the three extracts when compared with normal control $(P<0.01)$ group.

In line with IPGTT, similar outcomes were obtained with Oral Glucose Tolerance Test. At $60 \mathrm{~min}$, after glucose load the concentration of blood glucose were remarkably elevated to $(11.3 \pm 0.23 \mathrm{mmol} / \mathrm{L})$ in the normal control group, followed by the groups treated with Cissus quadrangularis $(9.0 \pm 0.13 \mathrm{mmol} / \mathrm{L})$, Woodfordia fruticosa Kurz $(8.3 \pm$ $0.13 \mathrm{mmol} / \mathrm{L})$ and C. anthelminticum $(7.5 \pm 0.23 \mathrm{mmol} / \mathrm{L})$ extracts (Fig. 2).Thereafter, at $120 \mathrm{~min}$, the elevated blood glucose levels had significantly decreased in the groups administered with C. anthelminticum $(4.3 \pm 0.09 \mathrm{mmol} / \mathrm{L})$, Woodfordia fruticosa Kurz $(6.2 \pm$ $0.12 \mathrm{mmol} / \mathrm{L})$, and Cissus quadrangularis $(7.2 \pm 0.15 \mathrm{mmol} / \mathrm{L})$ extracts, compared to that of the normal control $(10.5 \pm 0.15 \mathrm{mmol} / \mathrm{L})$ group. In the same manner, the reduction of blood glucose levels was sustained for all the 3 extract groups $(4.1 \pm 0.12,5.2 \pm 0.10$ and $6.5 \pm$ $0.19 \mathrm{mmol} / \mathrm{L}$, respectively) as well as for the control $(7.8 \pm 0.22 \mathrm{mmol} / \mathrm{L})$ group by $180 \mathrm{~min}$. A significant difference in blood glucose levels was observed between the times for all the 3 extracts $(P<0.001)$ respectively, when compared with the normal control $(P<0.01)$ group. 


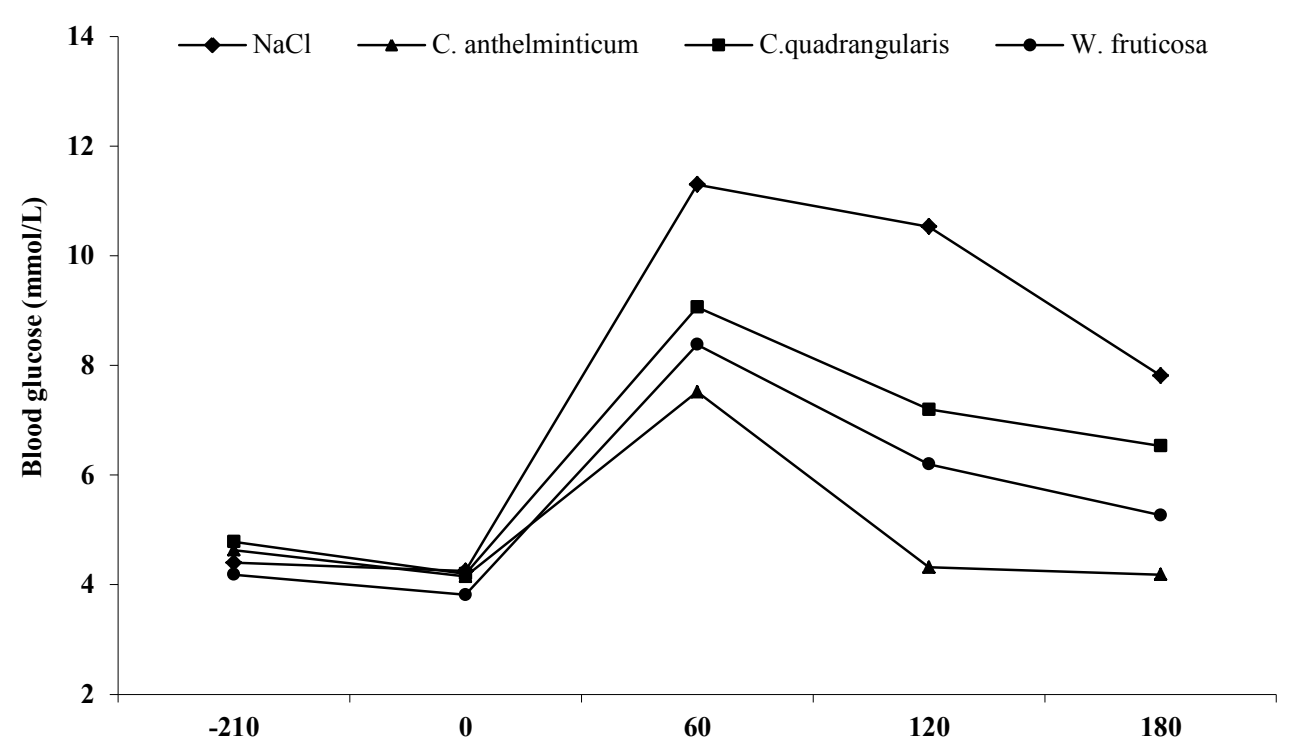

Time ( minutes)

Figure 2. Oral glucose tolerance test on C. anthelminticum, Cissus quadrangularis, and Woodfordia fruticosa Kurz extracts in normal fasted rats with glucose-induced hyperglycemia. Data are mean \pm SE. $\mathrm{n}=6$ for each group. $(P<0.001)$ for the three extracts when compared with normal control $(P<0.01)$ group.

The current study is a preliminary evaluation of the leaves from certain medicinal plants in the management of diabetes. The hypoglycemic activity of leaf extracts from 9 plants were screened and evaluated in normal rats. Of these nine plant extracts monitored, 5 (C. anthelminticum, Cissus quadrangularis, Woodfordia fruticosa Kurz, Sida acuta Burm $F$., and Parthenium hysterophorus L.) showed direct effects in reducing postprandial hyperglycaemia in normoglycaemic rats, while four (Vicoa indica, Vanda tessellata (Roxb.), Madhuca indica, and Xanthium strumarium) did not, or else might have an indirect effect. Overall, C. anthelminticum, Cissus quadrangularis, and Woodfordia fruticosa Kurzleaves demonstrated the highest hypoglycemic activity. This finding was further verified by the glucose tolerance tests in normal fasted rats.

Firstly, our findings on $C$. anthelminticum leaf extracts supports previous data in which seed fraction exhibited anti-diabetic and anti-hyperlipidemic activity in diabetic rats without any toxicity. ${ }^{6}$ The polyphenolic components from its seeds also exerted antihyperglycemic activity in maltose-loaded normal rats. ${ }^{7}$ Apart from this, the plant is used extensively in Ayurveda for the treatment of various disorders. Experimental studies have also reported different pharmacological effects of the seed extracts. ${ }^{13-14}$ In the same manner, extracts from different parts of Cissus quadrangularis and Woodfordia fruticosa Kurz also supports earlier findings ${ }^{9-11}$ as well as with other biological activities. ${ }^{15-20}$ Although acute toxicity studies point out the toxic nature of Parthenium hysterophorus L., it possess slight hypoglycemic effects. Thus, Parthenium hysterophorus $L$ should not be used in man until its toxicity has been more thoroughly determined. However, Sida acuta Burm F. also reported 
minor hypoglycemic effects, thus did not support any previous reports, despite of other pharmacological responses. $^{21-22}$

The different parts of $C$. anthelminticum, Cissus quadrangularis, and Woodfordia fruticosa Kurz plants are known to be a rich source of polyphenolic compounds, ${ }^{7,9,23}$ therefore, our study plausibly propose that involvement of different active compounds in the extracts, including phenols might play an important role in the reduction of elevated blood glucose levels. ${ }^{24}$ The availability of different medicinal plant parts in an appropriate time, the duration of these parts' lifespan, and the presence of the maximum amount of active compounds at that time are important issues in the pharmaceutical industry. Leaves remain available for a longer period on the plants compared to other plant parts, which is the reason we used leaves in our study. However, comparison of the distribution of the effective active compound levels between the different parts of these plants requires further study.

The aim in the management of diabetes mellitus is to attain blood glucose levels that are as close to normal as possible. ${ }^{25}$ In addition, controlling postprandial hyperglycemia could also prevent the development of macro and microvascular complications associated with diabetes. $^{26}$

Earlier studies on different plants, suggested that the administration of Mucuna pruriens, ${ }^{27}$ Cynara cardunculus,${ }^{28}$ Helicteres ixora, ${ }^{29}$ and Tournefortia hartwegiana ${ }^{30}$ extracts facilitate diabetic patients in controlling of postprandial hyperglycemia, thus enhanced glucose tolerance activity in the patients.In line with this, our findings postulated that utilizing C. anthelminticum, Cissus quadrangularis, and Woodfordia fruticosa Kurz leaf extracts as dietary or food supplements may be advantageous for diabetic patients in the control of postprandial hyperglycemia.

There were some limitations in this study, and the main explanation for our results may varies in different solvents used during extraction due to the presence of active compounds, or the methods used to determine the hypoglycemic effect. Firstly, we focused on the leaves to test for hypoglycemic activity rather than other parts of the plants. Secondly, testing of the extracts was not done in a dose-dependent manner.

\section{Conclusion}

The current study on 9 plants, displayed that the leaf extracts of C. anthelminticum, Cissus quadrangularis, and Woodfordia fruticosa Kurz exhibited the highest hypoglycemic activity in normal glycemic rats. Therefore, further study to assess anti-diabetic activity from different parts of these plants is suggested in a dose-dependent manner along with new approaches.

\section{Acknowledgments}

The authors sincerely thank the University of Malaya Animal Care Unit for providing the animal house facilities to carry out our preclinical studies. This Ph.D work was funded by (IPPP) Grant PS144/2008C from the University of Malaya.

\section{References}

1. Diabetes WHO Fact Sheet N³12 January 2011.

2. Bailey C and Day C, Diabetes Care.,1989,12, 533.

3. World Health Organization., World Health Organization: Geneva., 1994, 844,78-79.

4. JouadH, Haloui M, Rhiouani H, El HilalyJ, and Eddouks M., Journal of

Ethnopharmacology., 2001,77,175-182.

5. Grover JK, Yadav S and Vats V., Journal of Ethnopharmacology., 2002,81, 81-100. 
6. Fatima SS, Rajasekhar MD, Kumar KV, Kumar MT, Babu KR and Rao C A., Food Chem Toxicol, 2010, 48, 495-501.

7. Ani V and Naidu KA., European Food Research and Technology.2008, 226, 897-903.

8. Patel VS, Chitra V, Prasanna PL and Krishnaraju V., Indian JPharmacol, 2008, 40,183-5.

9.Chidambaram J and Carani Venkatraman., Food Chem Toxicol. 2010, 48(8-9), 2021-2029.

10. Charve BW, Jadhav DS, and Markendeya SK., The Socioscan, an internationalquarterly journal of social sciences. 2010, 2, 3-4.

11. Danik M. Martirosyan., Functional Foods for Chronic Diseases. 2007;3: 123-132.

12. Harborne JB, Phytochemical methods. Chapman and Hall: London, 1973, 113.

13. Srivastava A, Bartarya R, Tonk S, Srivastava SS and Kumari KM., Journal of Environmental Biology. 2008, 29, 669-672.

14. Purnima A, Koti BC, Tikare VP, Viswanathaswamy AHM, Thippeswamy AHM and Dabadi P. Evaluation., Indian Journal of Pharmaceutical Sciences.,2009, 71, 461.

15. Srisook K, Palachot M, Mongkol N, Srisook E and Sarapusit S., J Ethnopharmacol 2011, 133, 1008-14.

16. Kumar M, Rawat P and Dixit P., Phytomedicine, 2010, 17, 993-9.

17. Choi HJ, Song JH, Bhatt LR and Baek SH., Phytother Res, 2010, 24,1292-6.

18. Chandan BK, Saxena AK and Shukla S., J Ethnopharmacol, 2008,119, 218-24

19. Shah AS and Juvekar AR., Pharm Biol. 2010, 48(9), 1066-1072.

20. Dabur R, Gupta A and Mandal TK., Afr J Tradit Complement Altern Med, 2007,4,313-8.

21. Karou D, Dicko MH, Sanon S, Simpore J and Traore AS., Jethnopharmacol 2003, 89, 291-4.

22. Sreedevi CD, Latha PG and Ancy P., J Ethnopharmacol 2009, 124, 171-5.

23. Bhattarai S and Raj Bhuju D., In Ethnomedicinal Plants. Science Publishers, 2011, 253268.

24. Mooradian AD and Thurman JE., Drugs, 1999, 57, 19-29.

25. Kobayashi Y, Suzuki M and Satsu H., J Agric Food Chem 2000,48,5618-23

26. Baron AD., Diabetes Res Clin Pract.,1998, 40, S51-S55.

27. Bhaskar A, Vidhya VG and Ramya M., Fitoterapia, 2008, 79, 539-543.

28. Nomikos T, Detopoulou P, Fragopoulou E, Pliakis E and Antonopoulou S., Nutrition Research., 2007, 27(12), 741-749.

29. Venkatesh S, Reddy DG, Reddy YSR, Sathyavathy D and ReddyBM., Fitoterapia., 2004, 75(3-4), 364-367.

30. Ortiz-Andrade RR, García-Jiménez S, Castillo-Espaňa P,Ramírez-Avíila G,

Villalobos-Molina R and Estrada-Soto S., JEthnopharmacol., 2007, 109, 48-53. 


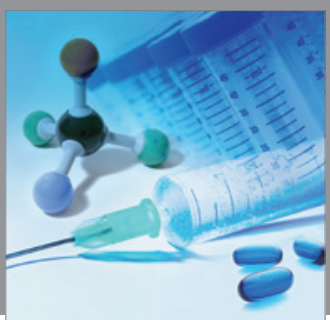

International Journal of

Medicinal Chemistry

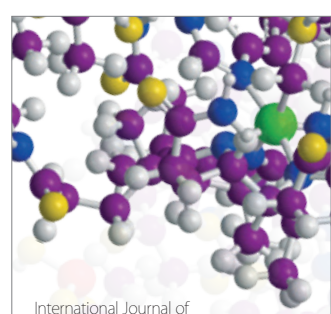

Carbohydrate Chemistry

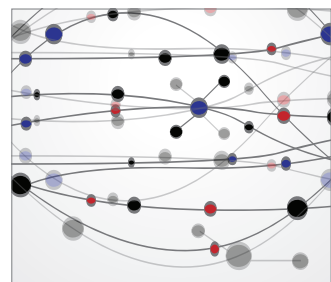

The Scientific World Journal
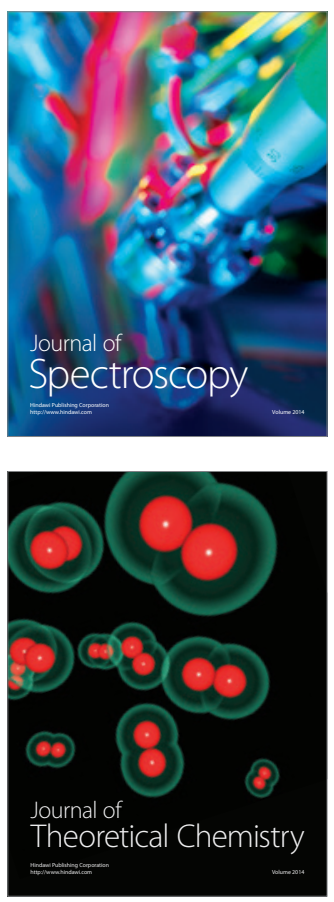
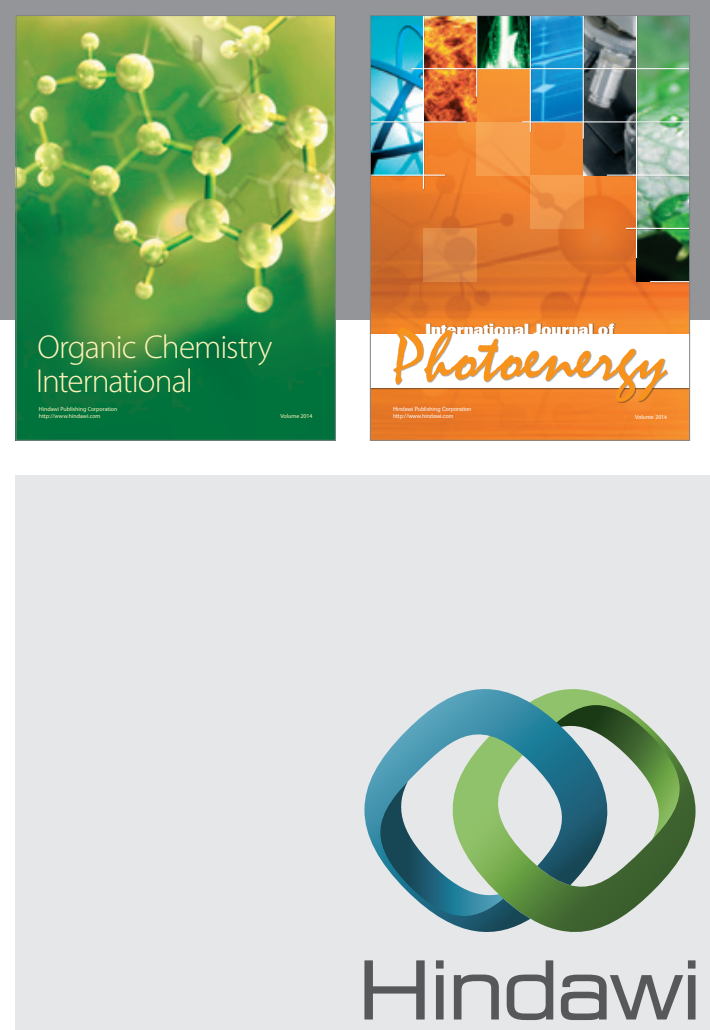

Submit your manuscripts at

http://www.hindawi.com
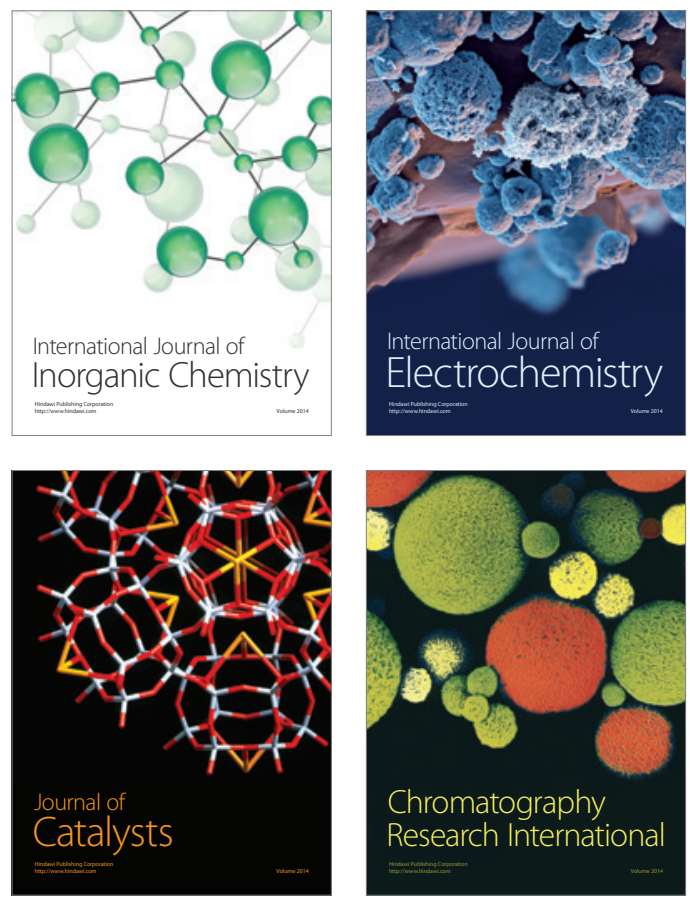
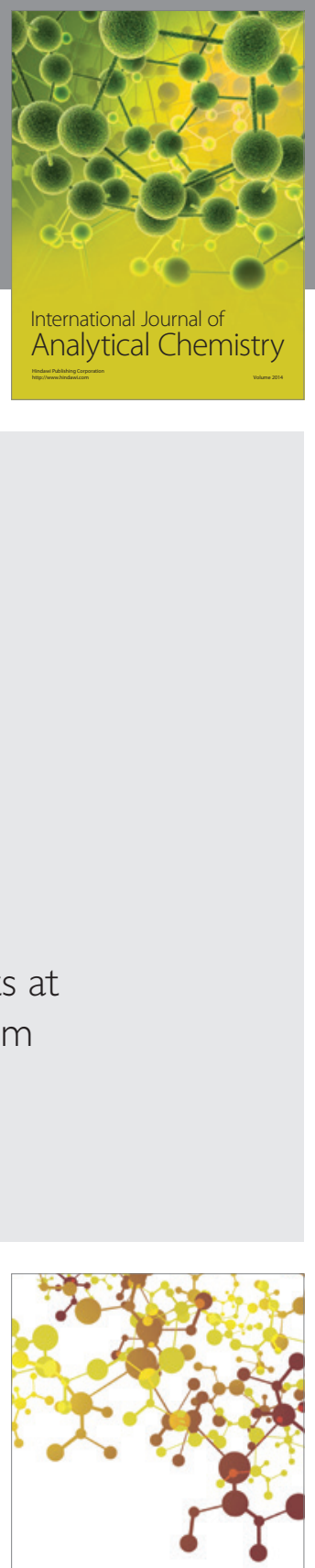

Journal of

Applied Chemistry
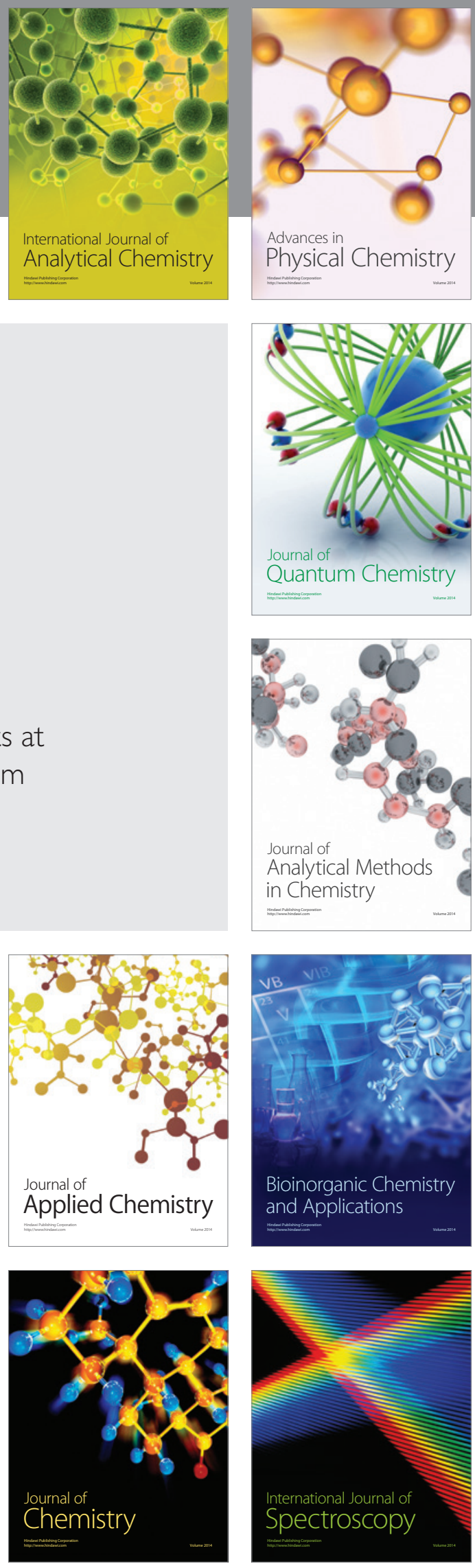